Original paper

\title{
Understanding Preparedness for Natural Hazards: A cross cultural comparison
}

\author{
Douglas Paton $^{1}$, Norio Okada ${ }^{2}$ and Saut Sagala ${ }^{3}$
}

Received: 22/11/2012 / Accepted: 20/02/2013 / Published online: 01/06/2013

\begin{abstract}
A key element in risk management in countries susceptible to experiencing natural hazards is facilitating preparedness. While several theories of preparedness have been developed, they have emerged in countries that are culturally individualistic. Recognition of the fact that the majority of disasters occur in countries that are predominantly collectivistic has identified a need to test the cross cultural applicability of theories of preparedness. This paper discusses some preliminary work on the cross cultural applicability of Paton's (2008) community engagement theory. Following a discussion of the cross cultural face validity of the content of this theory, the paper discusses evidence of cross cultural applicability of the theory using data from New Zealand, Japan, Indonesia and Taiwan. The results suggest that, irrespective of culture, the more citizens are able to collectively formulate their risk management needs and strategies and the more they perceive their needs as having been met through their relationship with civic agencies, the more likely they are to trust them and the information they provide, and to use information to decide to adopt hazard preparation measures.
\end{abstract}

Keyword: Natural hazards, preparedness, sustainability, resilience, culture comparison..

\section{INTRODUCTION}

A key risk management goal in countries whose populations are periodically exposed to natural hazard (e.g., earthquake, volcanic eruptions) activity is developing a sustained societal capacity to coexist with such activity. One element of such a strategy is developing the degree to which people and communities can reduce their risk by getting prepared (e.g., household emergency plans and resources, ability to work with others to confront local problems, capacity for self-reliance etc) in ways that increase their ability to cope with, adapt to and recover from hazard impacts (Paton 2006). However, and despite the attention and financial resources devoted to encouraging people to prepare, studies have consistently found that neither living in areas susceptible to hazard impacts nor just providing people with information on hazards and how they can manage their consequences appears to influence preparedness (Dow and Cutter, 2000; Lindell et al. 2009; Lindell and Perry 2004; Lindell and Whitney 2000; Paton, Smith and Johnston, 2000, 2005; Perry and Lindell, 2008). This work highlighted the fact that it was not information per se that determined whether or not people decide to

\footnotetext{
${ }^{1}$ School of Psychology, University of Tasmania, Launceston, Tasmania, 7250, Australia

${ }^{2}$ Graduate School of Science and Engineering, Kumamoto University Kurokami 2-40-1, Chuo Ward,

Kumamoto City, 860-8555, Japan.

${ }^{3}$ School of Architecture, Planning and Policy Development, Institute of Technology Bandung, Jl.

Ganesha 10, Bandung, Indonesia, 40132
} 
prepare for natural hazard events. Rather, it is how people interpret, for example, their circumstances and their risk, that determines what people do. The inclusion of interpretive processes in theories is particularly important when people are being called upon to make decisions about preparing for natural hazards whose infrequent nature generally precludes their finding out about risk and preparedness issues through direct experience. This suggested that advancing understanding of hazard preparedness could be pursued by investigating the personal, social and cultural influences on how people interpret risk and preparedness issues under the conditions of uncertainty that surround infrequent natural hazards. While personal and social factors have received considerable attention, the same is not true for cultural characteristics. This becomes an issue if the objective of preparedness research switches from just theory development to responding to calls for testing the applicability of theory on an international stage (Eiser et al. 2012).

The studies introduced in the previous paragraph have made significant contributions to enhancing understanding of hazard preparedness. However, their findings have been derived from research undertaken in western, culturally individualistic countries such as the United States and Australia. While this does not negate their applicability, the introduction of national culture as potential influence on people interpret risk and how they might manage their risk makes it pertinent to consider what this means for hazard research. The potential significance of this issue becomes evident from considering the worldwide distribution of disasters. Even a brief overview of this indicates that the location of the majority of the research on hazard preparedness does not match the distribution of disaster impacts. The fact that America and Oceania, the source of the majority of hazard preparedness research, accounts for only some $25 \%$ of disaster impacts highlights a need to ensure that preparedness theory can be extended to other regions. Determining whether this is possible, however, requires taking into consideration the cultural differences that exist between those countries which have dominated research and those where the majority of disasters occur, with the majority of disasters and the majority of losses from them occurring in Asia.

Although existing, empirically validated theories of hazard preparedness offer the possibility of their being used in other countries, this capability cannot be assumed. The countries in which the majority of the preparedness research has been undertaken (e.g., USA, Australia) and those in which the majority of disaster-related losses have occurred (Asia) fall at the extremes of several major cultural characteristics (Hofstede 2001). For example, countries such as the USA and Australia fall at the extreme individualistic end of the individualism-collectivism dimension (Brislin 2000; Norenzayan and Heine 2005; Triandis 1995). This raises issues regarding the applicability (see below) of western-developed theories in Asian cultures in which the majority of disasters occur and that are typically placed at the extreme collectivistic end of these cultural dimensions. The importance of asking questions of the cross cultural applicability of theories of preparedness theory has also been raised by the UN-ISDR through the IRDR program (Eiser et al. 2012).

The pursuit of this goal of determining whether theories developed in the occident can be used effectively in the orient is an activity justified by the theoretical and practical benefits that could accrue if supported. For example, if cultural equivalence could be demonstrated, it would provide a common basis for collaborative learning and research across national borders. This would increase the scope of the research that could be conducted through international cooperation by facilitating the development of complementary programs. Increasing the scope for international cooperation would also facilitate the spread of the benefits of research findings more widely. From a practical perspective, confirmation of cross-cultural equivalence would make information about how to facilitate preparedness available to countries that lack the resources to undertake this work themselves. It would also provide risk management agencies in different countries with access to a wider range of risk management options.

This paper discusses some preliminary work directed at responding to the challenge of assessing cross cultural equivalence in preparedness theory. Specifically, this paper examines the ability of Paton's (2008) community engagement theory of preparedness to account for differences in hazard preparedness when tested across two hazards (earthquake and volcanic) and in countries (New Zealand, Japan, Indonesia and Taiwan) that differ with regard to their cultural characteristics. 
This theory was developed to examine how interpretive process variables at individual and social levels interact to facilitate people's ability to change and adapt in ways that enhance their capacity to co-exist with hazardous elements in their environment by predicting hazard preparedness (see Paton 2006; 2008, Paton, Smith, Daly and Johnston, 2008; Paton et al., 2009 and Paton and McClure 2013 for fuller descriptions). This paper is not stating that this is the only theory, or the only variables, that could be examined in cross cultural comparison. This theory was selected for this initial comparison as it includes both individual-level (outcome expectancy) and community/social process (community participation and collective efficacy) variables. The inclusion of individual- and social-level process variables in this theory provides a useful starting point for studying cultures that differ with regard to their implicit emphasis on individual (individualistic cultures) and social (collectivistic) characteristics (Brislin 2000; Norenzayan and Heine 2005; Triandis 1995). In conducting this cross cultural analysis, the paper focuses on the individualism-collectivism cultural dimension. The reason for this is as follows.

Countries differ with regard to their relative positions on cultural dimensions (Matsumoto and Juang 2008). This paper draws on Hofstede's (2001) model of cultural dimensions. While Hofstede's model is only one of several developed to assess cultural similarities and differences, it was selected for the work discussed in this paper because it identified characteristics that could be implicated in the operation of preparedness processes and in determining the nature of preparedness outcomes (see below).

Hofstede's (2001) classification system affords a relatively parsimonious approach to assessing cultural similarities and differences between countries. Using cultural dimensions to study national differences means that, rather than having to study every country, the cross cultural applicability of theories can be assessed by comparing countries that differ with regard to their relative positions on these cultural dimensions. For example, if the explanatory utility of a theory can be demonstrated with countries that exist at opposite ends of a dimension (e.g., individualism-collectivism), it becomes possible to infer its applicability to those that fall in-between these extremes. Following research in some 72 countries, Hofstede identified how culture could be described in terms of the relative position of a country on the five dimensions of individualism-collectivism, power distance, uncertainty avoidance, masculinity-femininity, and long term orientation.

Individualism-Collectivism (I-C) describes the degree to which culture promotes, facilitates and sustains the needs/goals of autonomous individuals over those of the group (collective). Power distance (PD) assesses the degree to which people expect and accept that power is distributed unequally and accept the authority of those defined as superiors. Uncertainty avoidance (UA) defines the extent to which members of a culture feel threatened by uncertain, unknown or ambiguous situations. With regard to Masculinity-Femininity, a society is deemed masculine if social sex roles are clearly separated. Finally, Long term orientation is characterised by perseverance and sensitivity to status and is future-orientated.

The contents of this cultural classification identify dimensions whose nature could have significant implications for preparedness predictors, preparedness measures, and the relative weightings of activities within the preparedness process. For example, the relative position of a country on the I-C dimension could influence the comparative importance of person- versus group-level factors on preparedness decisions. Thus, if starting an exploration of preparedness from scratch, it would be possible to speculate that in more individualistic Western settings, individual level variables (e.g., outcome expectancy) would have a greater influence on decision making than collective processes. In highly collectivistic countries, the opposite would be predicted. Similar logic can be applied to other dimensions.

It could be hypothesised that as scores on the PD dimension increase, the more likely citizens in high PD countries would be to conform with edicts from formal sources of authority regarding preparedness without question. Similarly, as the relative position of a country on the UA dimension increases, the greater would be the motivation of its populace to (unquestioningly) comply with advice in order to reduce the uncertainty implicit in their hazard-scape. Finally, the emphasis long term orientation places on characteristics such as perseverance may influence such things as the ease 
with which preparedness can be sustained and become embodied in community life. These hypotheses, however, need to be put to the test to determine the degree to which they influence preparedness. This issue is particularly pertinent with regard to the I-C dimension as existing theories tend to favour the kind of intra-personal (e.g., outcome expectancy, coping style) characteristics over the interpersonal processes that could be of greater importance in more collectivistic cultures.

This chapter focuses on the I-C dimension. This is the most commonly studied, and arguably the most important, cultural dimension (Triandis 1995). It is argued here that it is particularly appropriate for the initial exploration of the cross-cultural equivalence of preparedness theory. This argument is based on the inference that characteristics such as Power Distance and Uncertainty Avoidance are high in the collectivist countries being compared in this paper (e.g., Indonesia, Taiwan - Hofstede 2001) and, importantly, could have more implicit influence on the adoption of preparedness measures (i.e., on the dependent variable) rather than on the predictors that are the substance of preparedness theories. Since it is the cross cultural equivalence of the predictors that is being examined in this paper, this is an important issue.

For example, both Power Distance and Uncertainty Avoidance can influence, either through automatic compliance (the action of high PD) or adoption to avoid uncertainty (the influence of high UA) the direct implementation of preparedness measures. Thus high PD and UA are cultural characteristics that could act directly on levels of preparedness in ways that could circumvent the predictors that represent the essence of preparedness theories. In contrast, I-C is a cultural characteristic that can be inferred to have direct implications for the nature of the decision process that preparedness theories (predictors) attempt to capture (e.g., the relative importance of intra- versus inter-individual and relationship variables). For this reason, this paper focuses on the I-C dimension. Having selected the individualism-collectivism dimension for this preliminary analysis, the next step is to assess whether their exist grounds for assuming the possibility that cross cultural equivalence for this theory could exist. This is discussed in the next section.

\section{THE COMMUNITY ENGAGEMENT THEORY}

The theory being examined in this paper suggests that interpretive process at the person level (outcome expectancy) interact with social (community participation, collective efficacy) and societal relationship (empowerment, trust) factors to predict preparedness (Paton 2008). This section discusses the rationale for using this community engagement theory for an exploratory analysis of cross cultural equivalence. This process commences with the outcome expectancy concept.

\subsection{Outcome expectancy}

In the theory being subjected to cross cultural comparison here, Paton (2008) proposed that a crucial interpretive process concerns people's beliefs regarding the hazard intensity and magnitude of hazard events and the amenability of such hazards to mitigation through individual action. This interpretive process is captured by the Outcome Expectancy concept (e.g., Bennet and Murphy 1997). Using the outcome expectancy concept to frame understanding of this interpretive process, the theory proposes that people will be disinclined to act if they believe that hazards are too catastrophic for personal action to make a difference to their safety or if they are highly fatalistic and possess external control beliefs. If, on the other hand, people believe that personal action can influence personal safety, people are motivated to start the preparedness process. However, believing individual action can be effective does not necessarily mean knowing what actions to perform or how to perform them. To get such information, people turn to others. 


\subsection{Social Influences on Hazard Interpretation}

Faced with complex and uncertain events, when they do not possess all the information they need themselves, peoples' perception of risk and how they might mitigate it, is influenced by information from others who share their interests and values (Earle 2004; Lion et al. 2002; Paton and Bishop 1996; Paton et al. 2006; Paton, Büergelt and Prior 2008; Poortinga and Pidgeon 2004). Thus levels of community participation will influence the availability of a social context in which people can formulate risk beliefs and actions. Discussion with other community members can increase the ability of people to collaborate to determine what consequences they could face, work out what would be an effective response, and then consider what information and resources they require to enact their mitigation strategies. One construct that encapsulates community members' ability to identify needs and formulate questions is collective efficacy. Collective efficacy is a measure of co-operation and assistance available within a community and community members' ability to assess their capabilities and resource needs and formulate plans to use resources to confront challenging tasks and it has demonstrated its utility in collectivistic cultures (Duncan et al. 2003; Paton, Gregg et al. 2008). Community participation was assessed using a measure developed by Eng and Parker (1994), and collective efficacy using a measure developed by Zaccaro et al. (1995).

\subsection{The Community-Agency Relationship}

The final set of social context variables derived from postulating that, given the infrequent and complex nature of the hazard events they may have to confront, it is possible to anticipate that community members' deliberations could identify information and resource needs that cannot be met within existing community contexts. Under these circumstances, people would turn to civic and expert sources to acquire the necessary information and resources.

The significance of including measures that encapsulate the quality of the relationship between community members and civic agencies derives from the important role trust plays when people make decisions under conditions of uncertainty (Siegrist and Cvetkovich 2000). As uncertainty increases, so does the importance people attribute to their trust beliefs about, and their past experiences with, the sources of information they turn to or have to rely on.

People's willingness to take responsibility for their own safety is increased, and decisions to prepare more likely, if they believe that their relationship with formal agencies is fair and empowering (e.g., agencies are perceived as trustworthy, as acting in the interest of community members) (Earle 2004; Eng and Parker 1994; Lion et al. 2002; Paton and Bishop 1996; Paton et al. 2005; Poortinga and Pidgeon 2004). If, however, the relationship between community members and an agency is not perceived as fair and empowering, the consequence is a loss of trust in the agency (i.e., the source of information), reducing the likelihood that people will use the information provided by an agency to guide their preparing. In other words, people's perception of the quality of their (historical) relationship with a source of information influences their interpretation of the value of information in a way that is independent of the information itself. Given the infrequent nature of hazards, it is argued here that people, irrespective of culture, will rely to some extent on the expert sources for information. This resulted in empowerment (assessed using a measure designed by Speer and Peterson 2000) and trust (examined with a measure developed by Dillon and Philips (2001)) being included as variables in the cross cultural test.

Intention to prepare was used as the dependent variable because of its ability to facilitate assessment when comparing hazards and cultures. Intentions can accommodate hazards with diverse preparedness needs (e.g., the measures required to adapt to volcanic hazards differ in several ways from those relating to earthquakes). Intention can also facilitate cross cultural comparison of communities that differ with regard to characteristics such as hazard history, culture, public education strategies and recommended preparedness measures. Intention has been found to be a good predictor of actual preparedness (Lindell and Perry 2004; Paton et al. 2005; Sheeran 2002) and has been demonstrated to be a good predictor of preparedness in a highly collectivistic culture. Paton et al. (2012) found a correlation of .61 between intention and hazard preparedness in a Portuguese (high 
collectivistic) sample. This provided the foundation for it being used in the present study as a proxy measure for conducting this comparative study. Before this theory can be used for cross cultural comparison, it is pertinent to consider the grounds for applying it in this way when comparing countries situated at different points on the individualism-collectivism cultural dimension.

\section{ASSESSING THE VALIDITY OF COMMUNITY ENGAGEMENT THEORY FOR CROSS CULTURAL COMPARISON}

The individualism-collectivism (I-C) dimension (Hofstede 2001) describes how cultures can be differentiated with regard to the social and psychological bases of people's beliefs and actions (Brislin 2000; Diener and Suh 2000; Norenzayan and Heine 2005; Poortinga 1997). For example, in more individualistic cultures (e.g., Australia, USA), people act consistently across situations in accordance with a self-concept that is relatively independent of social situation and in which achieving personal goals is a prominent objective. This makes it easy to see how person-level variables (e.g., outcome expectancy) would influence preparedness. It also means that if collective action occurs, it reflects personal choice regarding levels of collaboration and cooperation rather than a cultural predisposition. In contrast, in more collectivistic cultures (e.g., Indonesia), actions in most domains of daily life are underpinned by culturally-embedded beliefs that are reflected in shared purpose and activities that align with social norms to achieve collective goals through engaging in activities related to future goals that emphasize social relations (Diener and Suh 2000; Triandis 1995).

In light of these cultural differences, it becomes pertinent to ask whether there are grounds for believing that collective processes influence hazard preparedness in relatively more individualistic cultures and whether individual-level interpretive processes and beliefs influence preparedness in collectivistic countries. Only if affirmative answers to these questions are forthcoming will it become feasible to explore equivalence and then assess whether a valid cross-cultural theory can be developed. This paper discusses first reasons why affirmative answers to these questions might be expected.

The potential for social factors to influence beliefs and actions in Western, more individualistic countries, exists. For example, several studies have identified how, when faced with uncertainty, people turn to others who share their interests and values to help them reduce uncertainty and decide how to manage their risk (Earle 2004; Lion et al. 2002; Paton 2008). Family and members of the communities (e.g., workplaces, social and sporting clubs, churches etc.) with whom people interact regularly are prominent sources of this collective assistance. Thus processes such as community participation can be implicated as playing significant roles in the social construction of risk beliefs and preparedness decisions in members of individualistic cultures. This makes it feasible to consider comparing individualistic cultures with their collectivistic counterparts (for whom social context is, ostensibly, a more implicit driver of decision making and actions).

The next question is whether a basis for comparison exists in the other direction. In individualistic cultures (e.g., USA, Australia) it is not surprising that individual-level variables have been found to be prominent predictors of hazard preparedness. However, can the same be said for their collectivistic counterparts? Individualistic traits are being recognised for their potential to influence risk management choices in members of collectivistic cultures such as Japan (e.g., Bajek et al. 2008). The existence of empirical evidence indicating that person-level variables (e.g., outcome expectancy) can influence the choices made by citizens in collectivistic cultures offers additional justification for undertaking a comparison of the community engagement theory. An argument for expecting equivalence between members of individualistic and collectivistic cultures can also be made on the grounds of anticipated similarities in how people acquire the information required to help them deal with uncertainty.

The infrequent and complex nature of natural hazard events in all countries and the limited (if any) opportunities their citizens have to gain experience of either the hazard consequences they could experience or the effectiveness of mitigation measures they are being asked to adopt means that the climate of risk communication in all cultures is characterised by considerable uncertainty. Under this 
circumstance, if people are to identify the kinds of hazard consequences and demands they may have to contend with and find out what they might do to manage their risk, members of all cultures have to rely, at least to some extent, on information from expert scientific and risk management sources (e.g., through public education programs, attendance at public meetings etc.). This makes it pertinent to include community-civic agency relationships (e.g., the role of empowerment and trust) in a crosscultural comparison of hazard preparedness.

As with the other variables, the items comprising the intention measure were examined for cultural applicability (e.g., Paton et al. 2012). The intention measure comprised items that assessed people's intention to acquire hazard knowledge, increase actual preparedness, and to work with other people/civic agencies to develop knowledge and capability (Paton et al. 2005).

The above discussion suggests that irrespective of the cultural characteristics of the population being investigated, there exist grounds for believing that people's decisions about hazard preparedness result from interaction between individual beliefs, collective processes and competencies, and the quality of the relationship between people and the civic agencies. This provides additional justification for using the community engagement theory for a cross cultural comparison. To test for equivalence, analysis was conducted by comparing countries that differ substantially on their relative positions on the individualism-collectivism dimension.

Based on the above rationale for using the community engagement theory for a cross cultural comparison, the following hypotheses are proposed. If people hold negative outcome expectancy beliefs, it is hypothesised that this will reduce the likelihood of preparing. If people hold positive outcome expectancy beliefs, they will either proceed to prepare, or, if lacking the information they require, the relationship between POE and empowerment will be mediated by the structural processes (community participation and collective efficacy) used to articulate members needs and expectations. Next, it is hypothesized that empowerment mediates the relationship between structural factors and trust. Finally, it is hypothesized that trust predicts intentions to prepare.

\section{METHODS}

Analysis of whether the model can account for differences in levels of preparing across cultures was examined by comparing data from a combination of hazards and countries (Earthquake - New Zealand, Japan, Taiwan; Volcanic - New Zealand, Japan, Indonesia). For this exploratory analysis, comparison focused on the cultural dimension of Individualism-Collectivism (I-C) (Hofstede 2001). This dimension was selected as it is most extensively studied, and arguably the most significant, cultural dimension (Triandis 1995). The countries from which data were collected were selected because their relative positions on this dimension (the higher the score, the more collectivistic the culture) provided a relatively even spread of scores (Table 1) with data thus being collected from countries with low (New Zealand), medium (Japan) and high (Indonesia) collectivism.

Questionnaires containing the variables described below (see Table 2) were distributed randomly to households in Napier (New Zealand), Kyoto (Japan) and Tung Shia (Taiwan) to collect the earthquake data, and from Auckland (New Zealand), Kagoshima (Japan) and Mt. Merapi region (Indonesia). Participants were selected if they lived in the area at risk from the hazard in question. The rates of return (see Table1) were sufficient to ensure that the recommended 200-250 samples sizes for structural equation modelling (Byrne 2001; Tabachnick and Fidell 2007). Another issue raised by cross cultural analysis concerns the fact that the questions need to be translated.

The original questionnaire, and that administered in New Zealand was in English. The procedure recommended by Brislin (1986) was used to translate it into Japanese, Indonesian and Taiwanese. First, the English version was translated into each language. Secondly, that version was translated back into English by another independent translator. The original versions and back-translated versions were compared, examined for meaning errors, and corrections were made as required to ensure equivalent content. 
Table 1 The locations, cultural characteristics, and data collection information on the study areas

\begin{tabular}{cccccc}
\hline Location & $\begin{array}{c}\text { I - C } \\
\text { Score }\end{array}$ & $\begin{array}{c}\text { Volcanic } \\
\text { Location (N) }\end{array}$ & $\begin{array}{c}\text { Rate of } \\
\text { Return }\end{array}$ & $\begin{array}{c}\text { Earthquake } \\
\text { Location (N) }\end{array}$ & Rate of Return \\
\hline New Zealand & 79 & Auckland (297) & $74 \%$ & Napier (256) & $27 \%$ \\
Japan & 46 & Kagoshima (337) & $84 \%$ & Kyoto (251) & $13 \%$ \\
Taiwan & 17 & ---- & & Tung Shia (295) & $59 \%$ \\
Indonesia & 14 & Mt. Merapi (322) & $92 \%$ & --- & \\
\hline
\end{tabular}

The questionnaire did not include demographic data for two reasons. Firstly, a recent review (Becker, Paton, Johnston \& Ronan, in press) found that demographic characteristics had variable impacts on preparedness, with several studies finding no link at all between demographics and preparedness. The second reason stemmed from the fact that the present analysis focuses on interpretive processes. Thus the variables being assessed are independent of demographics. For example, it is concerned with whether people participate (and if this contributes to explaining variance in preparedness) and not in how people prepare (i.e., the groups or communities they are members of). If the latter were the object of the research, demographic characteristics could be relevant. This is not the case and hence demographic factors were not examined.

Because the model proposes that several independent variables interact to predict the dependent variable Structural Equation Model (SEM) as selected for the analysis. SEM can calculate multiple and inter-related dependence relationships simultaneously, allowing it to test the model as a whole and to show how well the data fit the hypothesized model (Goodness-of-Fit) (Byrne 2001). Of the questionnaires returned, fewer than 10 percent contained 'missing completely at random' data points and were replaced using mean substitution (Byrne 2001; Tabachnick and Fidell 2007).

\subsection{Analysis}

As recommended by Reisinger and Mavondo (2006), multiple fit indices were reported. The likelihood-ratio chi-square $\left(\chi^{2}\right)$ statistic is the primary measure of overall fit, and nonsignficant differences indicate a good fit of the model to the data. Noncentrality-based indices test the extent to which an incorrect model can be rejected (Reisinger and Mavondo 2006). The Root Mean Square Error of Approximation (RMSEA) assesses the amount of error present in the fit and is considered to produce accurate assumptions about model quality. Values $<0.05$ suggest a good fit to the data, while values between 0.05-0.08 reflect an adequate fit (Reisinger and Mavondo 2006). Values of the Goodness-of-Fit Index (GFI), the Normed Fit Index (NFI) and the Comparative Fit Index (CFI) greater than 0.95 are considered to reflect a good fit to the data (Reisinger and Mavondo 2006).

\section{RESULTS}

The Fit Indices are described in Tables 3 and 4. In each location, the $\chi^{2}$ values (Earthquake: NZ 5.919 (df 7); Japan - 7.474 (df 6); Taiwan-10.682 (df 10); Volcanic: NZ-9.02 df 11); Japan-229.6 (df 224), Indonesia-331.9 (df 340)) are not significant, the RMSEA values are under .05, and the remaining fit indices (with the exception of the NFI in Indonesia with a value of .93) exceeded the .95 cut-off. Tables 3 and 4 list the Relative Chi-square or Normed Chi-square (CMIN/DF) which is the chi-square fit index divided by degrees of freedom (Hu and Bentler 1998; Ullman 2007). Ullman 
suggests that a value of 2 or less reflects a good fit.

Overall, the fit indices indicate that the model was a good fit to the date in each location. The comparisons are summarized in Figures 1 and 2, which organizes the models by the position of their respective countries on Hofstede’s (2001) measure of Individualism-Collectivism.

Table 2 The variables, sources and scoring of the variables

\begin{tabular}{|c|c|c|c|c|}
\hline Measure & $\begin{array}{c}\text { Cronbach's } \\
\alpha\end{array}$ & Source & Items & Scoring Range \\
\hline $\begin{array}{l}\text { Positive } \\
\text { Outcome } \\
\text { Expectancy }\end{array}$ & 0.71 & $\begin{array}{l}\text { Bennet and Murphy } \\
\text { (1997) }\end{array}$ & 4 & $\begin{array}{l}1 \text { (Strongly disagree) - } 5 \text { (Strongly } \\
\text { agree) }\end{array}$ \\
\hline $\begin{array}{l}\text { Negative } \\
\text { Outcome } \\
\text { Expectancy }\end{array}$ & 0.64 & $\begin{array}{l}\text { Bennet and Murphy } \\
\text { (1997) }\end{array}$ & 4 & $\begin{array}{l}1 \text { (Strongly disagree) - } 5 \text { (Strongly } \\
\text { agree) }\end{array}$ \\
\hline $\begin{array}{l}\text { Collective } \\
\text { Efficacy }\end{array}$ & 0.71 & $\begin{array}{l}\text { Zaccaro et al. } \\
\text { (1995) }\end{array}$ & 12 & 1 (Very Low) -5 (Very High) \\
\hline Empowerment & 0.75 & $\begin{array}{l}\text { Speer and Peterson } \\
\text { (2000) }\end{array}$ & 4 & 1 (Not at all) - 5 (Always) \\
\hline Trust & 0.82 & $\begin{array}{l}\text { Dillon and Phillips } \\
\text { (2001). }\end{array}$ & 5 & $\begin{array}{l}1 \text { (Strongly disagree) - } 5 \text { (Strongly } \\
\text { agree) }\end{array}$ \\
\hline $\begin{array}{l}\text { Community } \\
\text { Participation }\end{array}$ & 0.83 & $\begin{array}{l}\text { Eng and Parker } \\
\text { (1994) }\end{array}$ & 5 & $\begin{array}{l}1 \text { (Strongly disagree) - } 5 \text { (Strongly } \\
\text { agree) }\end{array}$ \\
\hline $\begin{array}{l}\text { Intention to } \\
\text { Prepare }\end{array}$ & 0.74 & $\begin{array}{l}\text { Paton et al. } \\
(2005)\end{array}$ & 5 & 1 (No), 2 (Possibly), 3 (Definitely \\
\hline
\end{tabular}

Table 3 The fit indices from the SEM analyses - Earthquake

\begin{tabular}{ccccccc}
\hline & $\chi^{2} / \mathrm{df}$ & $\mathbf{p}$ & RMSEA & CFI & NFI & GFI \\
\hline NZ & 0.86 & 0.549 & 0.00 & .966 & .983 & .994 \\
Japan & 1.25 & 0.279 & 0.03 & .994 & .973 & .991 \\
Taiwan & 1.09 & 0.368 & 0.02 & .997 & .986 & .990 \\
\hline
\end{tabular}

The scores on this dimension are listed on the right hand side of each Figure. Sheeran's (2002) meta-analysis of 422 studies concluded that accounting for $28 \%$ of the variance in intentions would confer upon findings derived from using social cognitive models a medium to large effect size. For the earthquake analysis, the models accounted for 38\%, 29\% and 33\% of the variance in intentions to prepare in Napier, Kyoto and Tung Shia. For the volcanic analyses, the corresponding results were 37\%, 30\% and 65\% in Auckland, Kagoshima and Mt. Merapi respectively. These findings indicate that the findings represent medium to large effect sizes and this would allow the finding to be used as a guide to intervention planning.

Table 4 The fit indices from the SEM analyses - Volcanic

\begin{tabular}{lcccccc}
\hline & $\chi^{2} / \mathrm{df}$ & $\mathbf{p}$ & RMSEA & CFI & NFI & GFI \\
\hline NZ & 0.82 & 0.62 & 0.052 & 0.98 & 0.98 & 0.99 \\
Japan & 1.03 & 0.385 & 0.038 & 0.99 & 0.95 & 0.95 \\
Indonesia & 0.98 & 0.614 & 0.00 & 0.99 & 0.93 & 0.94 \\
\hline
\end{tabular}




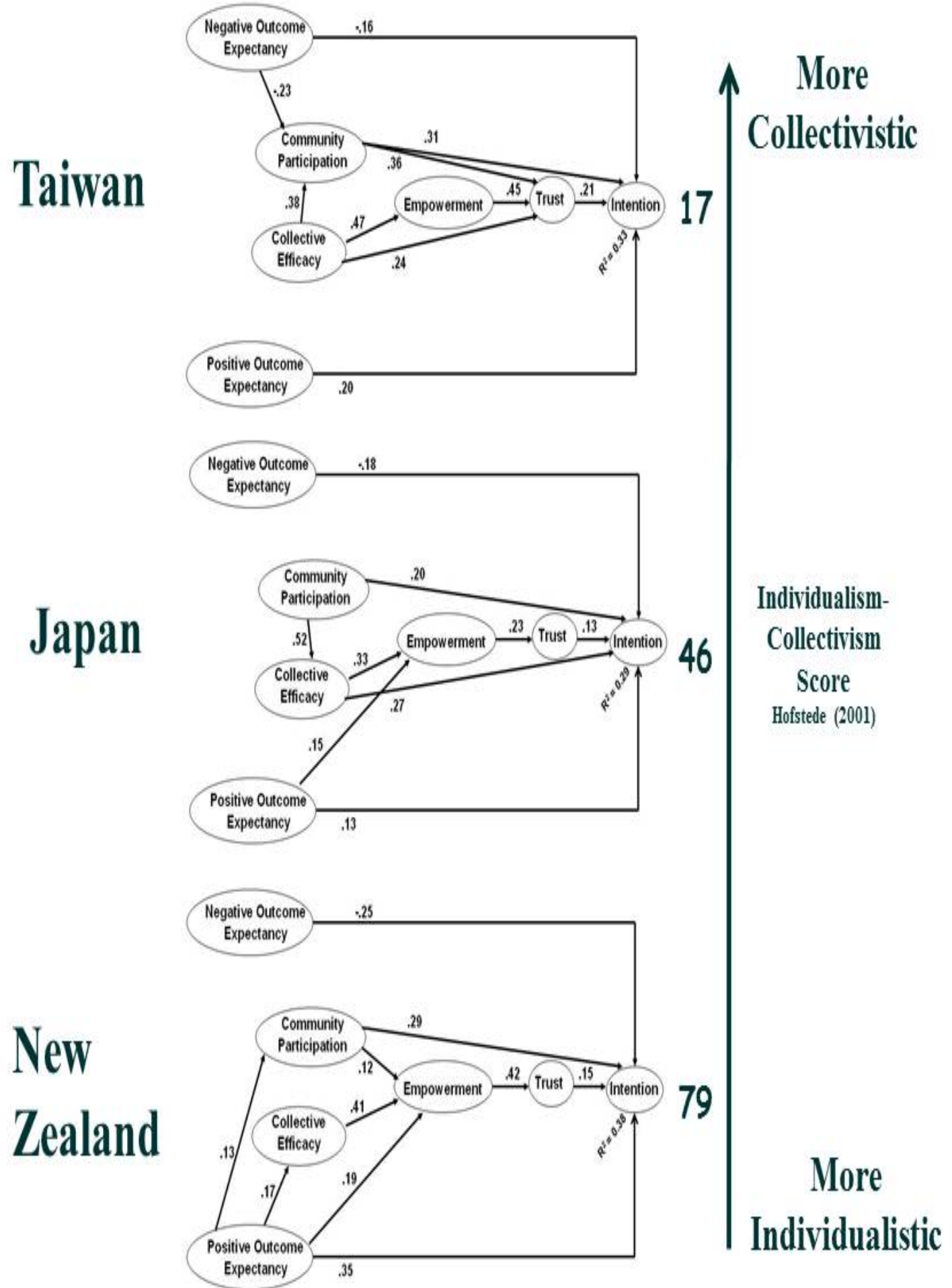

Figure 1 Summary of SEM models for the earthquake preparedness comparison. 


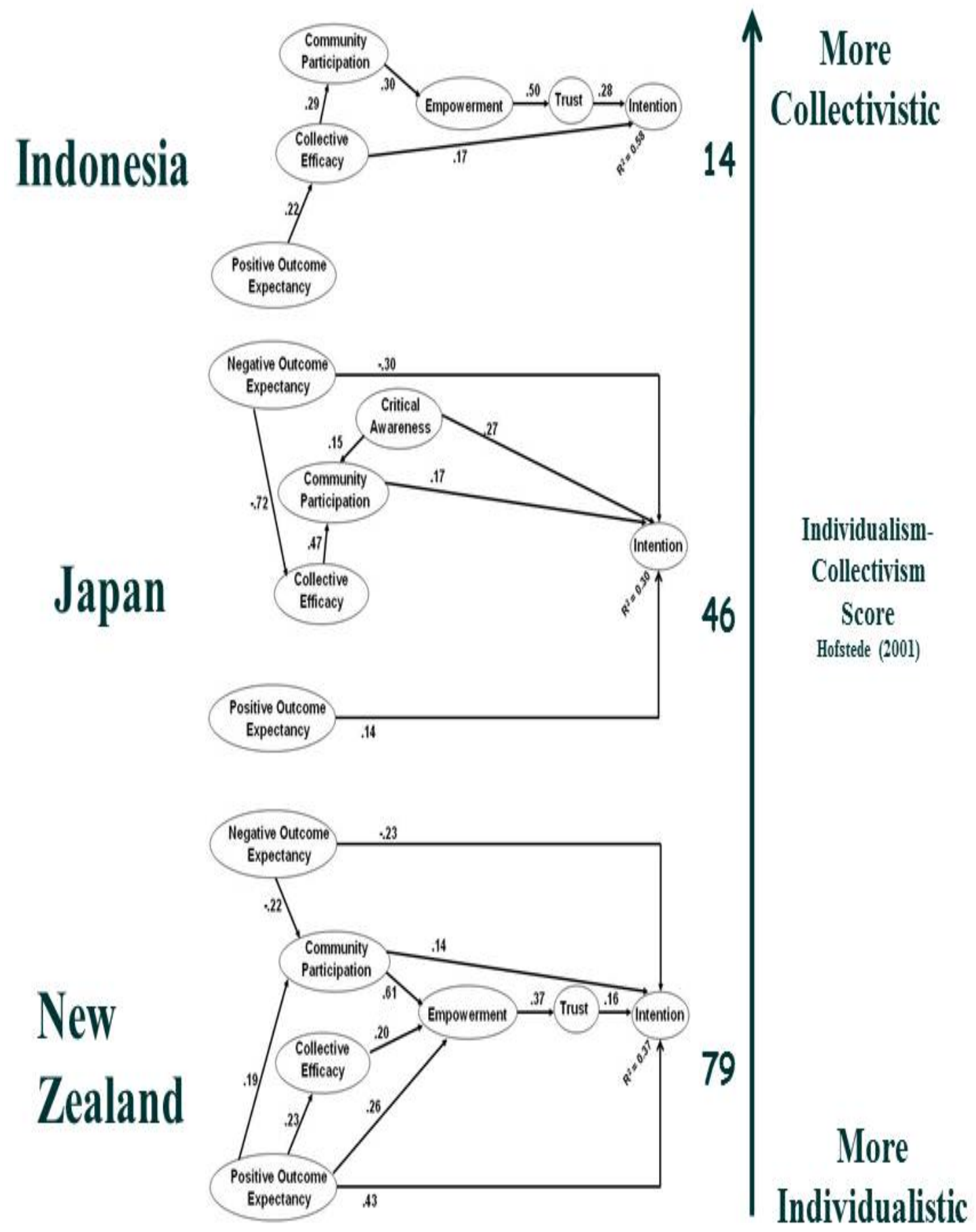

Figure 2 Summary of SEM models for the volcanic preparedness comparison.

\section{DISCUSSION}

The model was a good fit to the data in each location (Figures 1 and 2; Tables 3 and 4). The analyses offered support for the view that the relationship between personal beliefs and intentions is mediated by community (community participation and collective efficacy) and institutional (empowerment and trust) factors irrespective of cultural characteristics or hazard. An interesting finding in the Japanese volcanic analysis was that a better fit was obtained if empowerment and trust were excluded. This stands in contrast to the corresponding earthquake analysis which supported the model in its entirety. Given the fact that the theory was built around how trust influenced decision 
making and action under conditions of uncertainty, it is important to discuss possible reasons why a better fit for this analysis was obtained by excluding empowerment and trust.

It is possible to exclude nationality as a means of explaining this. The Japanese earthquake analysis supported the theory, and only the volcanic analysis identified a need to modify the model. This suggests that an explanation may be found in the relationship between people and the volcanic hazard present in the volcanic analysis. This explanation derives from the fact that the importance of trust and empowerment in decision making about risk and uncertainty is inversely related to the degree of familiarity people has with a situation (Earle and Cvetkovich 1995; Luhmann 1979; Mayer et al. 1995; Paton 2008; Siegrist and Cvetkovich 2000). This is reflected in the inclusion of situational influences in the conceptual model from which the theory was derived.

As familiarity increases so does the amount, quality and availability of information relevant to the situation people themselves possess or can more readily access. Residents in Kagoshima, from whom the Japanese volcanic data were obtained, are very familiar with volcanic hazards as a result of their experiencing ashfall and other volcanic hazards on average 1 day in 3 . In response to this high frequency of experiencing hazard impacts, Kagoshima residents experience hazard events regularly and are familiar with them and with what can be done to manage this risk. This has resulted in their developing, for example, building codes, ash removal practices and community attitudes and preparedness to facilitate continuity of societal functions during periodic volcanic episodes. The high frequency of experience of volcanic hazards in Kagoshima increases its citizens familiarity with the hazards and what works to manage their risk.

As hazard frequency increases in this area, so does the likelihood of people having had direct (e.g., having been affected by volcanic hazards) or indirect (e.g., witnessing the effects of volcanic activity in close proximity to where the live, knowing friends and family who have been affected etc.) experience of the events they are being asked to prepare for. This means that more information about volcanic hazards and volcanic preparedness is directly available to people and/or accessible from within their community, negating the need to acquire and evaluate information from other sources (Earle and Cvetkovich 1995; Luhmann 1979; Mayer et al. 1995; Paton 2008; Siegrist and Cvetkovich 2000).

The high familiarity respondents in Kagoshima have of volcanic hazards and their mitigation reduces their reliance on external sources for information about hazards and their mitigation. When this is the case, it is postulated that empowerment and trust (the variables that link people and risk management agencies) become less salient as influences on people's preparedness decisions. Dependence on external sources through empowerment and trust is therefore rendered unnecessary when people are able to make direct evaluations of the costs and benefits of preparing based on their personal accumulation of knowledge. This idea remains tentative until more searching analyses of familiarity and how it can be assessed and tested is undertaken.

In contrast, in the unfamiliar or novel situations (i.e., very infrequent hazard event frequency), that better describes the situation prevailing in the areas from which the remaining volcanic and all the earthquake data sets were obtained; reliance upon external expert sources would be correspondingly greater because the hazards are highly infrequent in these areas. Hence the significance of empowerment and trust as predictor variables in those areas. This reflects the fact that citizens in these areas face considerable uncertainty and are more reliant on expert and agency sources to help them acquire the information and advice required to inform their thinking and decision making about preparedness.

While the magnitude of the differences in the relative positions of each sample on the individualism-collectivism dimension could lead to expectations of differences in the relative importance of the individual versus social variables, this was not readily evident. One explanation for this derives from Triandis et al's (1986) work that introduced the concepts of allocentrism and idiocentrism to accommodate the fact that both individual and social factors influence behavior in all cultures through the enactment of cultural beliefs in everyday life, though they may differ in the relative importance of individual versus collective influences. This is evident in the data presented here with regard to the differences in the relative position of collective efficacy when comparing high 
versus low collectivism cultures. More work is needed to investigate this concept and its influence on behavior.

Overall, this comparison offers some support for the view that, irrespective of culture, the more citizens are able to collectively formulate their risk management needs and strategies and the more they perceive their needs as having been met through their relationship with civic agencies, the more likely they are to trust them and the information they provide, and to use information to decide to adopt hazard preparation measures. Demonstrating some cross cultural universality in how people deal with risk and uncertainty and make choices about whether or not to prepare has implications for risk management. However, before considering this, it is necessary to draw a distinction between the process of preparedness decision making and the content of the constituent variables. This is particularly important with regard to the community participation and collective efficacy variables as cultural characteristics can influence how these are developed, sustained and enacted. While these variables played comparable roles in the preparedness process in each sample, it is not possible to compare the content across samples directly. This results from the process-content difference introduced above. This issue is particularly pertinent when examining the specific role of culturespecific influences. For example, community participation in Japan may have been influenced by Jishubo (autonomous community-based organizations for disaster prevention) and its role in facilitating community member's satisfaction with and the quality of their learning about hazard management (Bajek et al. 2008). Furthermore, the effectiveness of Jishubo as a risk management mechanism is influenced by its operating under the auspices of an approach to societal governance that is unique to Japan.

Local government plays a direct role in organizing community participation in disaster prevention in Japan, with much disaster prevention-related policy in Japan being implemented through the governance scheme of Chonaikai (Bajek et al. 2008). In this regard, evidence for the effective role of mechanisms such as Jishubo, particularly if people are active volunteers (Bajek et al. 2008), provides tangible evidence of the benefits accruing from the presence of empowering links between communities and civic agencies within risk management strategies. Thus, through Chonaikai in general and Jishubo in particular, it is possible to identify culture specific content to the community participation (e.g., Jishubo affords opportunities for community members to participate in social activities that align with disaster prevention goals) and collective efficacy (e.g., Jishubo affords opportunities for community members to work together to define and resolve local risk management issues) measures in the Japanese sample. Furthermore, there is evidence of a relationship between involvement in Chonaikai organized events, community trust is civic agencies and preparedness (Bhandari et al. 2010), further reinforcing understanding how culturally specific processes could exercise some influence on the action of core theory variables such as trust.

Similar culture specific processes can be identified in Indonesia and Taiwan. In Indonesia, the traditional practice of gotong royong (mutual help) describes a culture-specific process that creates a mutual responsibility for acting to promote the well-being of a community. It thus describes a cultural mechanism that promotes participation in ways that involve people working collaboratively to deal with shared issues and opportunities. From this description, it is possible to anticipate how this could underling the role of the community participation and collective efficacy variables in the theory. In Taiwan, the location studied meant that data were collected from an ethnic group, the Hakka, which can be described by a unique cultural characteristic, the Hakka Spirit. This cultural predisposition has led to the development of ways of effectively managing regular damage to crops from typhoons. From this experience, it is evident how outcome expectancy beliefs could be reinforced by cultural practices. Other tenets of the Hakka Spirit facilitate reciprocal support and collaborative problem solving to manage both routine and hazard events. These examples illustrate the potential for culture specific mechanisms to contribute to explaining the development of variables such as community participation and collective efficacy and how they might be enacted to influence preparedness. Thus while a common preparedness process (e.g., irrespective of culture community participation represents a context in which risk beliefs are developed and enacted) can be described, it is important to appreciate and understand how cultural factors can introduce different content to the process. This brief discussion of culture specific processes introduces a need for research into comparative cultural 
analysis to specifically explore preparedness processes from emic perspectives and the insights that could be obtained from future research into comparing how culture-specific processes influence the content of the preparedness process across samples.

While cultural differences mean that replication of specific mechanisms such as Jishubo may not be totally tenable in culturally individualistic countries like New Zealand, it illustrates the importance of facilitating active community-civic agency interaction in risk management programs. Lessons can also flow in the opposite direction. Research in New Zealand on the origins of outcome expectancy beliefs and how they can be managed to facilitate hazard preparation measures could be used by to provide emergency management agencies in Japan, Indonesia and Taiwan with cost-effective access to strategies that could be used to influence outcome expectancy beliefs.

\section{CONCLUSION}

The work discussed here does not imply that this is the only theory that could be subject to a crosscultural validation or that the variables examined here are the only that could be similarly assessed. This theory and its constituent variables were selected for this initial examination of cross cultural equivalence because its inclusion of both individual- and social-level variables rendered it a useful starting point for comparing cultures whose characteristics could have had implications for the relative influence of individual- and social-level variables. There are several other theories, and variables, that can be examined in this way in future studies. A review of these theories and their constituent variables can be found in Paton and McClure (2013). Additional insights into variables whose cross-cultural equivalence could be assessed could be obtained from the analysis of culturespecific processes and then testing ideas developed from such analyses in Indonesia or Taiwan and applying them in more individualistic cultures.

A similar argument can be made regarding the cultural dimensions used to frame analyses of preparedness. The decision to focus on the individualism-collectivism dimension was made on the grounds that it was the dimension with the greatest influence theories of preparedness. Other cultural characteristics, such as power distance and uncertainty avoidance, could be investigated for their direct influences on adoption and whether, for example, prescriptive adoption influences other aspects of comprehensive preparedness such as knowledge of hazard behavior and characteristics and the conditions under which preparedness actions will be required. Similarly, long term orientation could be examined with regard to the hypothesized (see introduction to the paper) influence on sustained adoption.

The cross cultural assessment supports the view that the theoretical model can account for difference in levels of hazard preparedness intentions in New Zealand, Japan, Indonesia and Taiwan. The exception, but one that was predicted by the theories of trust incorporated into the community engagement theory, was the finding that trust and empowerment were not implicated in predicting preparedness for volcanic hazards in Kagoshima. This was explained in terms of high levels of experience and familiarity negating reliance on external sources.

The core variables in the model played comparable roles in the preparedness process irrespective of the country or hazard under investigation. The first common variable was outcome expectancy. The analyses indicated that people's beliefs about hazards and the actions proposed to mitigate their consequences influenced preparedness. The second set of variables described how characteristics (community participation) and competencies (collective efficacy) in people's social context provided a means of interpreting risk and actions. Social context factors were important in all countries, reinforcing findings that suggest that social networks influence the formulation of risk beliefs and mitigation strategies. The third concerned how people's perception of the quality of their relationship (e.g., whether it empowered them, whether they trusted the source) influenced the meaning imposed on information in way that was independent of the information per se.

By testing the model across different hazards (earthquake, volcanic) and cultures (New Zealand, 
Japan, Indonesia, Taiwan), it is evident that this theory has some all-hazards and cross-cultural utility. By demonstrating the existence of cross cultural equivalence in the preparedness process and being able to capture this process in a theory, the findings also highlight the potential for cross-fertilization in research and intervention that can accrue from cross-cultural collaboration. For example, confidence in the cross cultural applicability of a model of hazard preparedness would provide countries that lack the resources to research resilience themselves with a foundation for their risk management planning and provide opportunities for collaborative learning and research across national boundaries. Evidence for cross-cultural equivalence should not, however, be taken to imply that cultural factors can be ignored.

While similar fundamental processes can be implicated in accounting for differences in levels of hazard preparedness, it is important to note that cultural factors need to be accommodated in risk management planning. Additional work is needed to examine culture specific influences and the degree to which they represent homogenous influence on the social construction of risk and how such beliefs are enacted as preparedness behaviors. It is important to acknowledge that while culturespecific processes exist, they do not always influence behavior to the same extent for all (Bajek et al. 2008). A failure to accommodate cultural issues could increase vulnerability (e.g., because people will not support or adopt measures) or increase the risk of community fragmentation (e.g., fuelling disagreement amongst members of the same community, reducing future levels of community participation on hazard issues) and ignore the social capital of communities (community own capacity). Proposing measures that conflict with cultural beliefs or practices could increase distrust of civic authorities responsible for risk management and result in risk management being inconsistent with social justice principles and thus have the effect of reducing community resilience (Paton 2006; Vanhoebrouck and Sagala 2010). This work has additional implications for risk management in multicultural countries such as Australia and the USA.

In increasingly pluralistic societies, risk management strategies must be applied against a backdrop of growing diversity with regard to people's needs, perceptions, goals and expectations. Reconciling this diversity with the costs and benefits of hazard mitigation in fair and just ways is a demanding task and one that requires risk management strategies to be based on social justice principles. Community engagement in decision making about acceptable levels of risk and the acceptability of strategies used to mitigate this risk positively influence risk acceptance, increase community members' acceptance of responsibility for their own safety, and increase collective commitment to confront hazard consequences using community-led mitigation strategies as found in many community based disaster risk management (CBDRM) principles.

\section{REFERENCES}

Bajek, R. Matsuda, Y, and Okada, N. (2008). Japan's Jishu-bosai-soshiki community activities: analysis of its role in participatory community disaster risk management, Natural Hazards 44, 281-292.Becker, J., Paton, D., Johnston, D.M. and Ronan, K. (in press). Salient Beliefs about Earthquake Hazards and Household Preparedness. Risk Analysis. DOI: 10.1111/risa.12014

Bennett, P., and Murphy, S. (1997). Psychology and health promotion. Buckingham: Open University Press.

Bhandari, R., Okada, N., Yokomatsu, and Ikeo, H. (2010). Analyzing urban ritual with reference to development of social capital for disaster resilience: A case study of Kishiwada. Proceedings of IEEE International Conference on Systems, Man and Cybernetics, pp. 3477-3482.

Brislin, R. (1986). The wording and translation of research instruments. In W. Lonner and J. Berry (Eds.), Field methods in cross-cultural research. Newbury Park: Sage Publications.

Brislin, R. (2000). Understanding culture's influence on behavior. Melbourne: Wadsworth.

Byrne, B. M. (2001). Structural equation modelling with AMOS: Basic concepts, applications, and programming. New Jersey: Lawrence Erlbaum.Diener, E., \& Suh, E. M. (2000). Culture and subjective well-being. Cambridge, MA: MIT Press. 
Diener, E., and Suh, E. M. (2000). Culture and subjective well-being. Cambridge, MA: MIT Press.

Dillon, J., and Phillips, M. (2001). Social Capital, Perth: Curtin University Press.

Dow, K and Cutter, S.L. (2000). Public orders and personal opinions: household strategies for hurricane risk assessment, Environmental Hazards, 2, 143-155.

Duncan, T.E., Duncan, S.C., Okut, H., Strycker, L.A., and Hix-Small, H. (2003). A Multilevel Contextual Model of Neighbourhood Collective Efficacy, American Journal of Community Psychology 32, 245-252.

Earle, T.C. (2004). Thinking aloud about trust: A protocol analysis of trust in risk management, Risk Analysis 24, 169-183.

Earle, T. C., and Cvetkovich, G. T. (1995). Social trust: Towards a cosmopolitan society. Westport, CT.: Praeger.

Eiser, J.R., Bostrom, A., Burton, I., Johnston, D.M., McClure, J., Paton, D., van der Pligt, J., \& White, M.P. (2012). Risk interpretation and action: A conceptual framework for responses to natural hazards. International Journal of Disaster Risk Reduction. 1, 5-16.

Eng, E., and Parker, E. (1994). Measuring community competence in the Mississippi Delta: The interface between program evaluation and empowerment, Health Education Quarterly 21, 199-220.

Hofstede, G. (2001). Culture's Consequences: Comparing Values, Behaviors, Institutions and Organizations across Nations. Thousand Oaks CA.: Sage.

Hu, L., and Bentler, P. M. (1998). Cutoff criteria for fit indexes in covariance structure analysis: Conventional criteria versus new alternatives. Structural Equation Modeling, 6, 1-55.

Lindell, M. K., Arlikatti, S., and Prater, C.S. (2009). Why do people do what they do to protect against earthquake risk: Perception of hazard adjustment attributes. Risk Analysis, 29, 1072- 1088.

Lindell, M.K., and Perry, R.W. (2004). Communicating Environmental Risk in Multiethnic Communities. Thousand Oaks, CA.: Sage Publications.

Lindell, M.K. and Whitney, D.J. (2000). Correlates of household seismic hazard adjustment adoption, Risk Analysis 20, 13-25.

Lion, R., Meertens, R.M., and Bot, I. (2002). Priorities in information desire about unknown risks, Risk Analysis 22, 765-776.

Luhmann, N. (1979). Trust and power. Chichester: Wiley.

Matsumoto, D., and Juang, L. (2008). Culture and psychology. Belmont CA: Thompson/Wadsworth.

Mayer, R. C., Davis, J. H., and Schoorman, F. D. (1995). An integrative model of organizational trust. Academy of Management Review, 20, 709-734.

Norenzayan, A., and Heine, S.J. (2005). Psychological universals: What are they and how can we know?, Psychological Bulletin 131, 763-784.

Paton, D. (2006). Disaster Resilience: Building capacity to co-exist with natural hazards and their consequences. In D. Paton \& D. Johnston (Eds), Disaster Resilience: An integrated approach. Springfield, Ill.: Charles C. Thomas.

Paton, D. (2008). Community Resilience: Integrating individual, community and societal perspectives In K. Gow and D. Paton (Eds) The Phoenix of Natural Disasters: Community resilience. New York: Nova Science Publishers.

Paton, D., and Bishop B. (1996). Disasters and communities: Promoting psychosocial well-being. In D. Paton and N. Long (Eds) Psychological Aspects of Disaster: Impact, Coping, and Intervention, Palmerston North: Dunmore Press. 
Paton, D., Buergelt, P.T., and Prior, T. (2008). Living with Bushfire Risk: Social and environmental influences on preparedness. Australian Journal of Emergency Management, 23, 41-48.

Paton, D., Gregg, C.E., Houghton, B.F., Lachman, R., Lachman, J., Johnston, D.M., and Wongbusarakum, S. (2008). The impact of the December $26^{\text {th }} 2004$ tsunami on coastal Thai communities: Assessing adaptive capacity. Disasters, 32,106-119.

Paton, D., Houghton, B.F., Gregg, C.E., McIvor, D., Johnston, D.M., Buergelt, P.T., Larin, P., Gill, D.A., Ritchie, L.A., Meinhold, S. and Horan, J. (2009). Managing Tsunami Risk: Social context influences on preparedness. Journal of Pacific Rim Psychology, 3, 27-37.

Paton, D., Kelly, G., Buergelt, P.T., and Doherty, M. (2006). Preparing for Bushfires: Understanding intentions, Disaster Prevention and Management 15, 566-575.

Paton, D., and McClure, J. (2013 -in press). Preparing for Disaster: Building household and community capacity. Springfield, Ill., Charles C. Thomas

Paton, D., Smith, L.M., Daly, M., and Johnston, D.M. (2008). Risk Perception and Volcanic Hazard Mitigation: Individual and social perspectives. Journal of Volcanology and Geothermal Research, 172, 179-188.

Paton, D., Smith, L.M. and Johnston, D. (2000). Volcanic hazards: Risk Perception and Preparedness. New Zealand Journal of Psychology, 29, 84-88.

Paton, D., Smith, L.M., and Johnston, D. (2005). When good intentions turn bad: Promoting natural hazard preparedness, Australian Journal of Emergency Management 20, 25-30.

Paton, D. Tedim, F and Shand, H. (2012). Adapting to bushfire risk: Social context influences on housing safety. In D. Paton and F. Tedim (Eds) Wildfire and Community: Facilitating Preparedness and Resilience. Springfield, Ill.: Charles C. Thomas.

Perry, R.W. and Lindell, M.K. (2008). Volcanic risk perception and adjustment in a multi-hazard environment, Journal of Volcanology and Geothermal Research 172, 170-178.Poortinga, Y. (1997). Towards convergence? In J. Berry, Y. Poortinga, \& J. Pandey (Eds.), Theory and method: Vol. 1. Handbook of Cross Cultural Psychology (2 ${ }^{\text {nd }}$ ed., pp. 347-387). Boston, MA: Allyn \& Bacon.

Poortinga, Y. (1997). Towards convergence? In J. Berry, Y. Poortinga, \& J. Pandey (Eds.), Theory and method: Vol. 1. Handbook of Cross Cultural Psychology ( $2^{\text {nd }}$ ed., pp. 347-387). Boston, MA: Allyn \& Bacon.

Poortinga, W., and Pidgeon, N.F. (2004). Trust, the asymmetry principle, and the role of prior beliefs, Risk Analysis 24, 1475-1486.

Reisinger, Y., and Mavondo, F. (2006). Structural equation modeling: Critical issues and new developments, Journal of Travel and Tourism Marketing 21, 41-71.

Sheeran, P. 2002. Intention-behaviour relations: A conceptual and empirical review. In W. Stroebe, and M. Hewstone (Eds.), European review of social psychology (pp. 1-36). Chichester, England : Wiley.

Siegrist, M., and Cvetkovich, G. (2000). Perception of hazards: The role of social trust and knowledge, Risk Analysis 20, 713-719.

Speer, P.W., and Peterson, N.A. (2000). Psychometric properties of an empowerment scale: Testing cognitive, emotional and behavioural domains, Social Work Research 24, 109-118.

Tabachnick, B. G., and Fidell, L. S. (2007). Using multivariate statistics ( $5^{\text {th }}$ ed.). Boston: Allyn \& Bacon.

Triandis, H.C. (1995) Individualism and collectivism. Boulder, CO.: Westview.

Triandis, H.C., Bontempo, R., Betancourt, H., Bond, M., Leung, K., Brenes, A., Georgas, J., Hui, H. C., Marin, G., Setiadi, B., Sinha, J.B.E, Verma, J., Spangenberg, J., Touzard, H. \& de Montmollin, 
G. (1986). The measurement of etic aspects of individualism and collectivism across cultures. Australian Journal of Psychology, 38(3), 257-267.

Ullman, J. B. (2007). Structural equation modeling. In B. G. Tabachnick \& L. S. Fidell (Eds.), Using multivariate statistics ( $5^{\text {th }}$ ed., pp. 676-780). Boston: Pearson Education, Inc.

Vanhoebrouck, P. and Sagala, S. (2010). Not so helpless victims: Social Capital Roles in the 2009 West Sumatra Earthquake Recovery, Research Report of International Federation of Red Cross and Red Crescent (IFRC), Indonesia

Zaccaro, S.J., Blair, V., Peterson, C., and Zazanis, M. (1995). Collective Efficacy. In: J.E Maddux (Ed.), Self efficacy, adaptation, and adjustment: Theory, research, and application, pp. 305-328. New York: Plenum Press. 